\title{
Mechanical Response of Carbon Nanotube Bundle to Lateral Compression
}

\author{
Dina U. Abdullina ${ }^{1}\left(\mathbb{C}\right.$, Elena A. Korznikova $2,3{ }^{\circledR}$, Volodymyr I. Dubinko ${ }^{4}$, Denis V. Laptev ${ }^{5}(\mathbb{C}$,

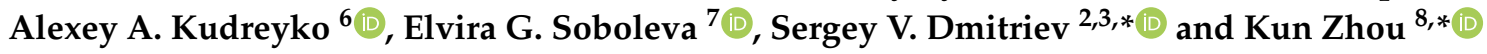 \\ 1 Department of Physics and Technology of Nanomaterials, Bashkir State University, Zaki Validi St. 32, \\ 450076 Ufa, Russia; dina.abdullina25@gmail.com \\ 2 Institute for Metals Superplasticity Problems, Russian Academy of Sciences, Khalturin St., 39, \\ 450001 Ufa, Russia; elena.a.korznikova@gmail.com \\ 3 Institute for Molecule and Crystal Physics, UFRC, RAS, Oktyabrya Av., 151, 450075 Ufa, Russia \\ 4 NSC Kharkov Institute of Physics and Technology, 61108 Kharkov, Ukraine; vdubinko@hotmail.com \\ 5 B. Verkin Institute for Low Temperature Physics and Engineering, 61103 Kharkiv, Ukraine; \\ laptev.denis.18@gmail.com \\ 6 Department of Medical Physics and Informatics, Bashkir State Medical University, Lenina St. 3, \\ 450008 Ufa, Russia; alexkudreyko@mail.ru \\ 7 Yurga Institute of Technology (Branch), National Research Tomsk Polytechnic University, \\ 652050 Yurga, Russia; sobolevaeno@mail.ru \\ 8 School of Mechanical and Aerospace Engineering, Nanyang Technological University, 50 Nanyang Avenue, \\ Singapore 639798, Singapore \\ * Correspondence: dmitriev.sergey.v@gmail.com (S.V.D.); kzhou@ntu.edu.sg (K.Z.)
}

Received: 29 February 2020; Accepted: 7 April 2020; Published: 10 April 2020

\begin{abstract}
Structure evolution and mechanical response of the carbon nanotube (CNT) bundle under lateral biaxial compression is investigated in plane strain conditions using the chain model. In this model, tensile and bending rigidity of CTN walls, and the van der Waals interactions between them are taken into account. Initially the bundle in cross section is a triangular lattice of circular zigzag CNTs. Under increasing strain control compression, several structure transformations are observed. Firstly, the second-order phase transition leads to the crystalline structure with doubled translational cell. Then the first-order phase transition takes place with the appearance of collapsed CNTs. Further compression results in increase of the fraction of collapsed CNTs at nearly constant compressive stress and eventually all CNTs collapse. It is found that the potential energy of the CNT bundle during deformation changes mainly due to bending of CNT walls, while the contribution from the walls tension-compression and from the van der Waals energies is considerably smaller.
\end{abstract}

Keywords: carbon nanotube bundle; plane strain conditions; lateral compression; equilibrium structure; thermal stability; chain model

\section{Introduction}

Carbon atoms can create a huge number of allotropes because four valence electrons can form the $s p^{1}, s p^{2}$ and $s p^{3}$ bond configurations. The action of van der Waals forces produces a variety of secondary structures including structures with a translational symmetry such as fullerite crystal [1-3], graphite [4,5], and crystals made of carbon nanotubes (CNTs) [6-8]. Such van der Waals crystals have properties not exhibited by their structural elements, for example, chemical properties typical for molecular crystals and peculiar mechanical properties related to deformability of the structural units [1-8]. This work is devoted to the mechanical properties of CNT bundles under lateral compression. 
CNTs have superior mechanical properties such as tensile strength up to $63 \mathrm{GPa}$, tensile Young's modulus up to $1.3 \mathrm{TPa}$, and ultimate fracture strain up to about 10\% [9-12]. In addition, they are flexible, have low weight, high thermal and electrical conductivity, which makes them very promising for a number of applications [13-16]. CNT forests are produced by means of various experimental techniques [17-21] and used for making super-strong ropes [7,22], fibers [23-27], fillers for composite materials [28-30], solid lubricants [30-33], etc.

Mechanical properties of vertically aligned CNT forests and brushes have been tested with respect to tension [7,22-27] and compression [34-41]. Lateral compression of CNT bundles or isolated CNTs is also of interest [42-46]. Horizontally aligned CNT array are produced from as grown vertically aligned CNT bundles by drawing, rolling, and shear pressing [47-50]. It has been shown that CNT bundles are linear elastic up to $1.5 \mathrm{GPa}$ hydrostatic pressure with the volume compressibility of $0.024 \mathrm{GPa}^{-1}$ [51]. In the experimental study [52] it has been shown that the deformation of CNT bundles under non-hydrostatic pressure becomes irreversible for pressures above $5 \mathrm{GPa}$. Experimental and computational works on mechanical properties of CNTs have been discussed in the review [53].

It is well accepted by the scientific community that computational studies become increasingly important in evaluation of the mechanical properties of nanomaterials helping to reduce the cost and speed up the research. A number of computational approaches have been developed for the study of structures based on CNTs in addition to the well-known molecular dynamics method. Deformation mechanisms of CNT forest have been studied with mesoscopic modeling in [54,55]. A continuum thin shell theory is capable of describing large deformations of CNTs [56]. Mechanical properties of CNTs under transverse loading have been studied in [8]. In the review [57] the power of the nonlocal beam, plate and shell theories in modeling mechanical properties of nanomaterials is described. Application of the continuum beam theory has been demonstrated in [58]. Simulation of the mechanical properties and failure of the CNT bundles have been performed using a nonlinear coarse-grained stretching and bending potentials [59].

Notably, CNTs of diameter greater than a threshold value can exist in circular and collapsed forms due to the competition between CNT wall bending and van der Waals interactions [60-63].

In the existing works devoted to the mechanics of CNT bundles, little attention was paid to the discussion of structure evolution under lateral compression up to large strain levels. This problem is interesting from the standpoint of fundamental science because materials with highly deformable structural units should have peculiar mechanical properties and CNT bundle is an example of such material, as CNT cross section can obtain various shapes under pressure. Unlike dense materials, CNT crystal can demonstrate very high compressibility in the elastic region and highly stretchable or compressible elastic materials are actively studied in recent years [64-66]. Practically, CNT bundles can be used, e.g., for protection against shocks and vibrations $[34,67,68]$.

Here the mechanical properties of CNT bundle under lateral compression will be addressed in frames of the chain model offered in [69] and modified for the CNT bundle in [70]. The efficiency of the chain model in modelling secondary $s p^{2}$-carbon structures such as folded and scrolled carbon nanoribbons has been demonstrated in a series of works [69-75].

\section{Simulation Setup}

Lateral biaxial compression of CNT bundle is considered in this study under plane strain condition. The CNTs are aligned along the $z$-axis creating a triangular lattice in cross-section. For definiteness, the zigzag CNTs are considered. In Figure 1, the computational cell is schematically shown and the geometrical parameters are specified: $a$ is the distance between carbon atoms in the CNT wall, $d$ is the distance between the walls of neighboring CNTs, $D$ is CNT diameter and $A=D+d$ is the distance between centers of neighboring CNTs. The atoms move on the $(x, y)$ plane and each atom stands for a rigid row of carbon atoms oriented along the $z$-axis. The computational cell includes $20 \times 24$ CNTs (the case of $2 \times 2$ CNTs is presented in Figure 1). Each CNT has 30 atoms and total number of atoms in the computational cell is $N=20 \times 24 \times 30=14400$. Much smaller computational cell can be used for 
simulation of structures with a long-range order, but for irregular structures a representative volume should be considered and, as it will be shown later, the cell with $20 \times 24$ CNTs is sufficiently large.

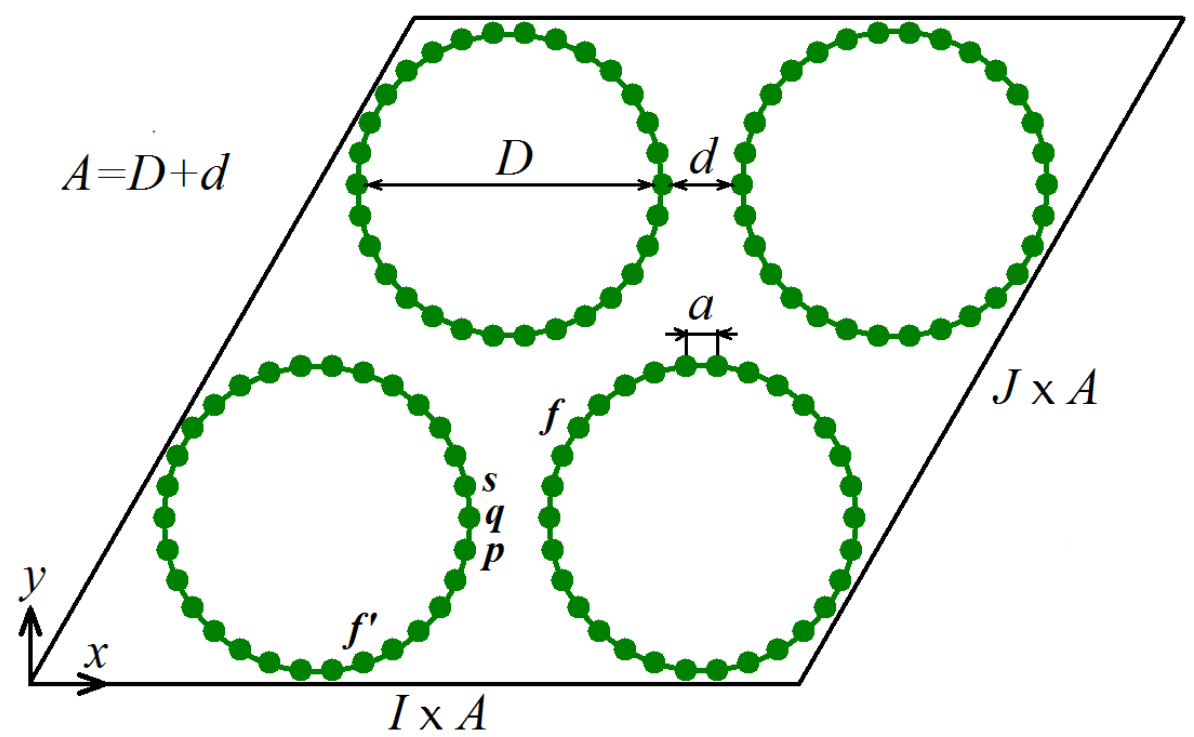

Figure 1. Geometry of the computational cell with $I \times J$ nanotubes $(I=J=2$ in this case, while $I=20$, $J=24$ in simulations). Each zigzag CNT is represented by 30 carbon atoms that move on the $(x, y)$ plane. Each atom stands for a row of atoms oriented normal to the $(x, y)$ plane, which moves as a rigid body. Geometry parameters are as follows: $a$ is the distance between carbon atoms in the CNT wall, $d$ is the distance between the walls of neighboring CNTs, $D$ is CNT diameter and $A=D+d$ is the distance between centers of neighboring CNTs. The computational cell in the form of a parallelogram has the sides $I \times A$ and $J \times A$. The computational cell is subject to the periodic boundary conditions. Indices $p, q, s, f$, and $f^{\prime}$ are used to describe the interatomic interactions.

Each atom has two degrees of freedom, the components of the displacement vector in the $(x, y)$ plane, with the total number of degrees of freedom equal to $2 N=28800$. Periodic boundary conditions are used in both directions.

Numerical values of the geometry parameters are as follows. The equilibrium interatomic distance in graphene is $\rho=1.418 \AA$. The equilibrium distance between rigid atomic rows oriented along the $z$-axis is $a=\rho \sqrt{3} / 2=1.228 \AA$, CNT diameter is $D=a / \sin (\pi / 30)=11.75 \AA$, the equilibrium distance between CNT walls under zero pressure is $d=3.088 \AA$, and the distance between centers of neighboring CNTs is $A=D+d=14.838 \AA$. Note that CNT diameter is relatively small in our study and separate CNT in the absence of external forces can have only circular stable configuration.

In our simulations the units of time, energy and distance are picoseconds, $\mathrm{eV}$, and angstrom, respectively. In these units the mass of carbon atom is $M=12 \times 1.0364 \times 10^{-4}$.

The CNT bundle is described by the Hamiltonian (total energy) $[69,70]$

$$
H=K+U_{\mathrm{B}}+U_{\mathrm{A}}+U_{\mathrm{vdW}}
$$

where the four terms in the right-hand side give the kinetic energy, the energy of valence bonds, valence angles, and van der Waals non-valence interactions, respectively. These energies are fully described in [70]. Here we reproduce the expressions for the energies for the sake of the reader. In Figure 1, indices $p, q$, and $s$ number nearest atoms in the wall of a CNT and $f$ is the atom belonging to a different CNT, while $f^{\prime}$ belongs to the same CNT as the atom $q$ and the distance between $q$ and $f^{\prime}$ is not less than $3 a$. Then the energies in the right-hand side of Equation (1) are specified as follows. 
Kinetic energy is

$$
K=\frac{M}{2} \sum_{q=1}^{N}\left|\dot{\mathbf{r}}_{q}\right|^{2}
$$

where $\mathbf{r}_{q}$ is the radius-vector of $q$-th atom, overdot means differentiation with respect to time, and summation is over all atoms in the computational cell. We note that the kinetic energy term is not taken into account in this work, since only the relaxational dynamics of atoms is considered, but we present it for completeness of the description of the model.

The energy of valence bonds is defined by the harmonic potential

$$
U_{\mathrm{B}}=\sum_{q=1}^{N} \frac{k}{2}\left(\left|\mathbf{r}_{q}-\mathbf{r}_{s}\right|-a\right)^{2}
$$

which is summation over the bonds connecting nearest atoms (see Figure 1) and the number of such bonds is equal to the number of atoms. The longitudinal stiffness of graphene is well reproduced when $k=405 \mathrm{~N} / \mathrm{m}[69]$.

The energy of valence angles is given by the anharmonic potential

$$
U_{\mathrm{A}}=\sum_{q=1}^{N} \epsilon\left[1+\cos \left(\theta_{p q s}\right)\right], \quad \text { where } \quad \cos \left(\theta_{p q s}\right)=\frac{\left(\mathbf{r}_{q}-\mathbf{r}_{p}, \mathbf{r}_{s}-\mathbf{r}_{q}\right)}{\left|\mathbf{r}_{q}-\mathbf{r}_{p}\right|\left|\mathbf{r}_{s}-\mathbf{r}_{q}\right|}
$$

which is summation over the valence angles formed by the atoms $p, q$, and $s$ (see Figure 1) and the number of such angles is equal to the number of atoms. Bending stiffness of graphene is well reproduced when $\epsilon=3.50 \mathrm{eV}$ [69].

The energy of van der Waals non-valence interactions is given by the $(5,11)$ Lennard-Jones potential

$$
U_{\mathrm{vdW}}=\frac{1}{2} \sum_{q, f=1 ; q \neq f}^{N} \frac{\varepsilon}{6}\left[5\left(\frac{\sigma}{\left|\mathbf{r}_{q}-\mathbf{r}_{f}\right|}\right)^{11}-11\left(\frac{\sigma}{\left|\mathbf{r}_{q}-\mathbf{r}_{f}\right|}\right)^{5}\right],
$$

with the parameters $\varepsilon=0.00166 \mathrm{eV}$ and $\sigma=3.61 \AA$ [69]. Here summation is over all interatomic bonds connecting atoms $q$ and $f$ within the cut-off radius of $6 \AA$, and for atoms belonging to the same CNT (denoted as $f^{\prime}$ in Figure 1), as it was already mentioned, the bonds shorter than $3 a$ are not taken into account. Note that the summands in Equation (5) give the interaction potentials between pairs of rigid atomic rows oriented along the $z$-axis. This potential was obtained by summation of the C-C interatomic energies described by the $(6,12)$ Lennard-Jones potential. The net interaction energy between two atomic rows is best fitted by the $(5,11)$ Lennard-Jones potential [69].

In the course of fitting the model parameters, strong sensitivity of the simulation results to small changes in the parameters was not observed.

In this study, mechanical properties of CNT bundle under lateral biaxial compression in plane strain conditions with $\varepsilon_{x x}=\varepsilon_{y y} \leq 0$ and $\varepsilon_{x y}=0$ are evaluated. The strain state of the structure is characterized by the absolute value of the volumetric strain $|\theta|=\left|\varepsilon_{x x}+\varepsilon_{y y}\right|$. Temperature effect is not taken into consideration and the perturbation-relaxation molecular dynamics simulations are carried out. Equilibrium structures are found after each increment of compressive volumetric strain $|\Delta \theta|=0.02$ at $T=0 \mathrm{~K}$. The simulation algorithm is as follows. Incremental compressive strain is applied with the step $\Delta \varepsilon_{x x}=\Delta \varepsilon_{y y}=-0.0025$. Each strain increment is followed by the perturbation of coordinates of the atoms by adding random displacements uniformly distributed over the range from $-10^{-6}$ to $10^{-6} \AA$. After that, the potential energy of the system is minimized using the gradient method and the equilibrium structure is obtained. It is assumed that the energy minimization is complete when the absolute value of the maximal atomic force does not exceed $10^{-10} \mathrm{eV} / \AA$. 


\section{Results and Their Discussion}

Here we report the simulation results starting from the structure analysis and then moving to the analysis of the energy-strain and stress-strain relations.

\subsection{Structure Evolution}

During step-wise biaxial compression the structure of CNT bundle exhibits several qualitative transformations (the results for the small volumetric strain can be found in [70]). In Figure 2a-d, structures are shown for $|\theta|=0.06,0.10,0.20$ and 0.40 , respectively. In (a) CNTs still preserve their nearly circular cross sections, while in (b) one can see periodic structure of CNTs having elliptic cross sections. In contrast to the structure in (a), the structure in (b) has translational cell with two CNTs, which is formed as the result of second-order phase transition [70]. For the compressive volumetric strain of $|\theta|=0.20$, as shown in (c), collapsed CNTs appear in the structure as the result of the first-order phase transition. Further compression results in the increase of the collapsed CNT fraction and at $|\theta|=0.40$ all CNTs are collapsed, as it can be seen in (d).

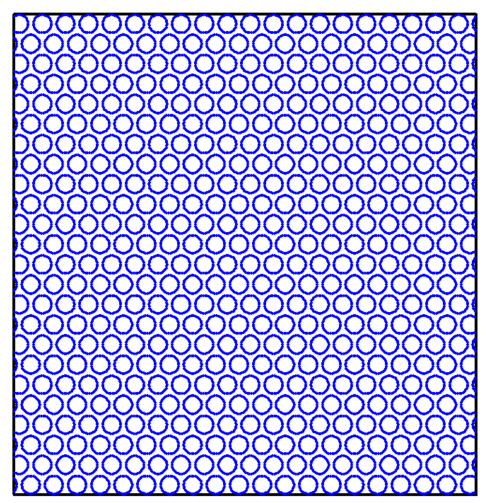

(a) $|\theta|=0.06$

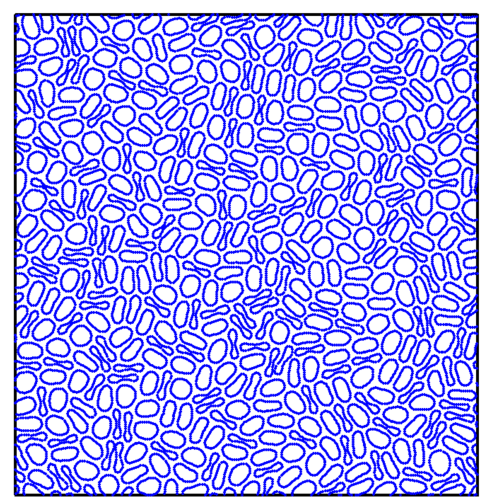

(c) $|\theta|=0.20$

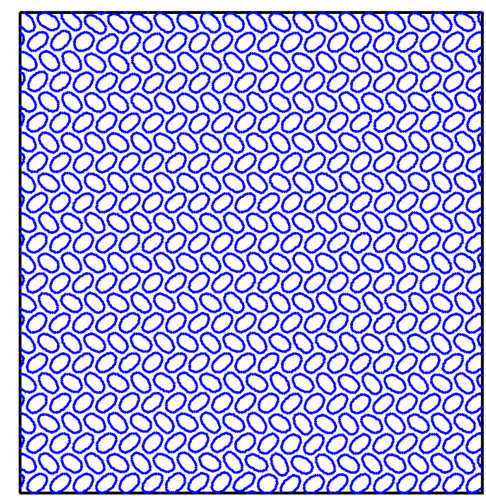

(b) $|\theta|=0.10$

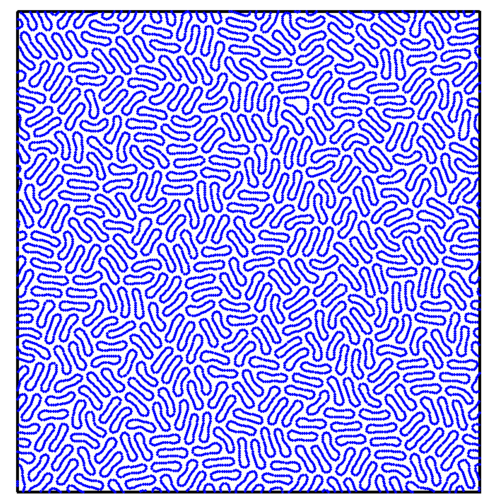

(d) $|\theta|=0.40$

Figure 2. Structure of the CNT bundle shown for (a-d) $|\theta|=0.06,0.10,0.20$ and 0.40 , respectively.

For simulation of the crystalline structures shown in Figure 2a,b a much smaller computational cell can be used and even DFT simulations are possible for these cases. For the irregular structures presented in Figure 2c,d, a computational cell with a few CNTs is insufficient for evaluation of the averaged mechanical properties.

In order to quantify the structural changes, we define the ellipticity of CNT cross section

$$
\eta=\frac{b}{a}
$$


where $a$ and $b$ are the largest and smallest dimensions of the cross section. We also define the orientation angle $\alpha$ of the CNT cross section. These parameters are shown in the inset of Figure 3a, left panel.

Parameters $\eta$ and $\alpha$ are calculated for each CNT and then the 20-bin histograms are constructed. In Figure 3a-d, the histograms are shown for $\eta$ at left and for $\alpha$ at right for $|\theta|=0.06,0.10,0.20$ and 0.40, respectively. From this figure one can see that at $|\theta|=0.06$ all CNTs have $\eta \approx 1$ and various orientation angles. CNTs in Figure 2a, being under biaxial compression, have slightly flattened faces with the cross section resembling hexagonal prisms. The expected long diameters of the prisms have orientations of 30,90 and 150 degrees. However this effect is very weak and the cross section profiles are perturbed by the discreteness of the CNT walls and we see other peaks in Figure 3a, right panel. For nearly cylindrical CNTs the orientation angles mainly reflect the presence of the computational noise. In (b) one can see a drastic change of the histograms. Here all CNTs have $\eta \approx 0.6$ and orientations about 30 and 150 degrees (see Figure $2 b$ ). In (c) the histogram for $\eta$ has a sharp peak at $\eta \approx 0.2$ and a broad hump centered at $\eta \approx 0.5$. The sharp peak stands for the collapsed CNTs and the hump represents the non-collapsed CNTs with various ellipticity. The orientation angle histogram in (c) does not reveal preferable orientation angles (see Figure 2c). In (d), the broad hump disappears in the distribution of $\eta$ since all CNTs collapse (see Figure 2d). On the other hand, the histogram of orientation angles in (d) features three distinct peaks at 0,60 and 120 degrees.
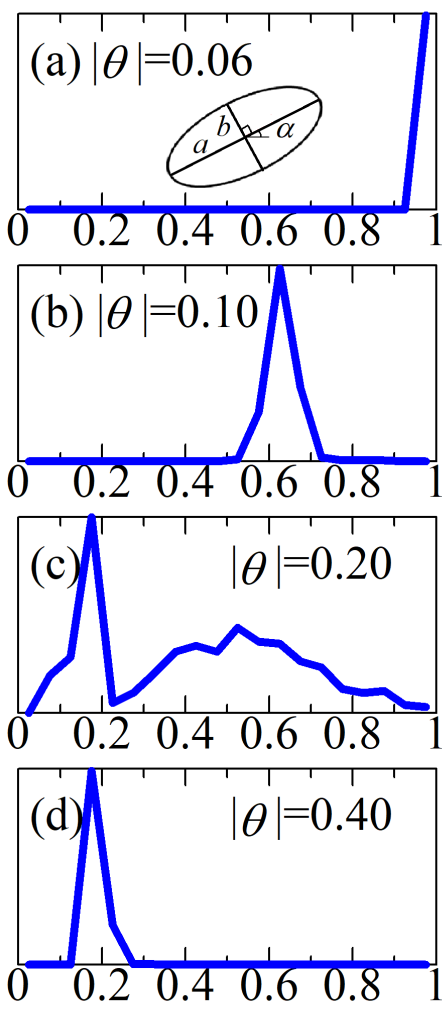

$\eta$
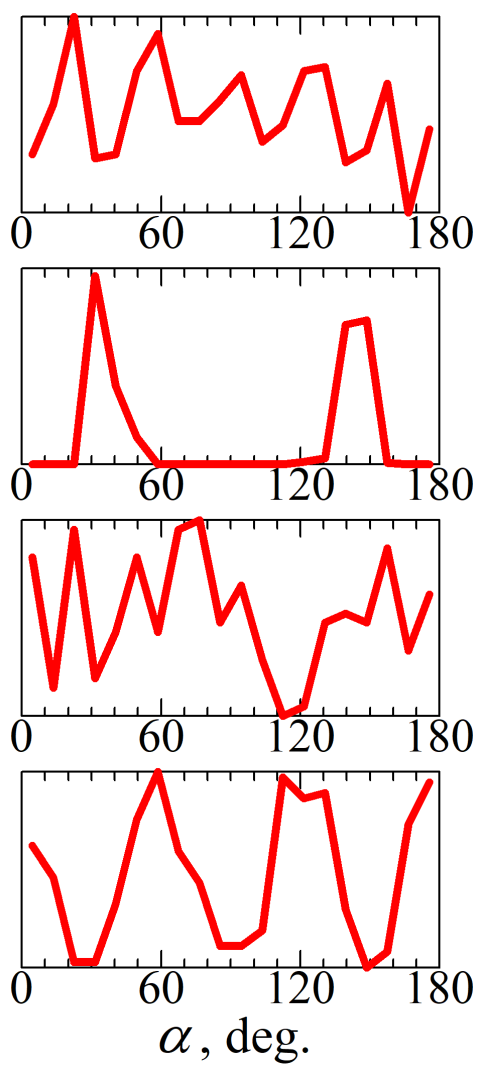

Figure 3. 20 bin histograms showing the distribution of CNT cross section ellipticity $\eta=b / a$ (at left) and orientation angle $\alpha$ (at right). Parameters $a, b$ and $\alpha$ are defined in the inset in (a), left panel.

\subsection{Energy-Strain and Stress-Strain Curves}

In Figure 4, as the functions of the volumetric compressive strain, we plot the potential energy of the relaxed CNT bundle, $U$, and its three components: the energy of valence bonds $U_{\mathrm{B}}$, valence angles $U_{\mathrm{A}}$, and van der Waals interactions $U_{\mathrm{vdW}}$, see Equation (1).

For compressive volumetric strain less then 0.09 , before the collapsed CNTs appear in the system, the potential energy $U$ increases with strain quadratically. When structure compression takes place 
due to the increase in the fraction of compressed CNTs, $U$ grows with strain linearly. For $|\theta|>0.37$, when nearly all CNTs are collapsed, potential energy starts to increase with strain faster than linearly.

It can be seen from Figure 4 that dominant contribution to the potential energy $U$ comes from the energy of the valence angles $U_{\mathrm{A}}$ and the other two components are much smaller. In the range of volumetric strain $0.09<|\theta|<0.37$ a reduction of the energy of van der Waals interactions $U_{\mathrm{vdW}}$ is observed. This is explained by the formation of new van der Waals bonds when CNTs collapse and their walls start to interact. Smallness of the energy of the valence bonds $U_{\mathrm{B}}$ means that CNT walls in the considered type of loading can be assumed as inextensible.

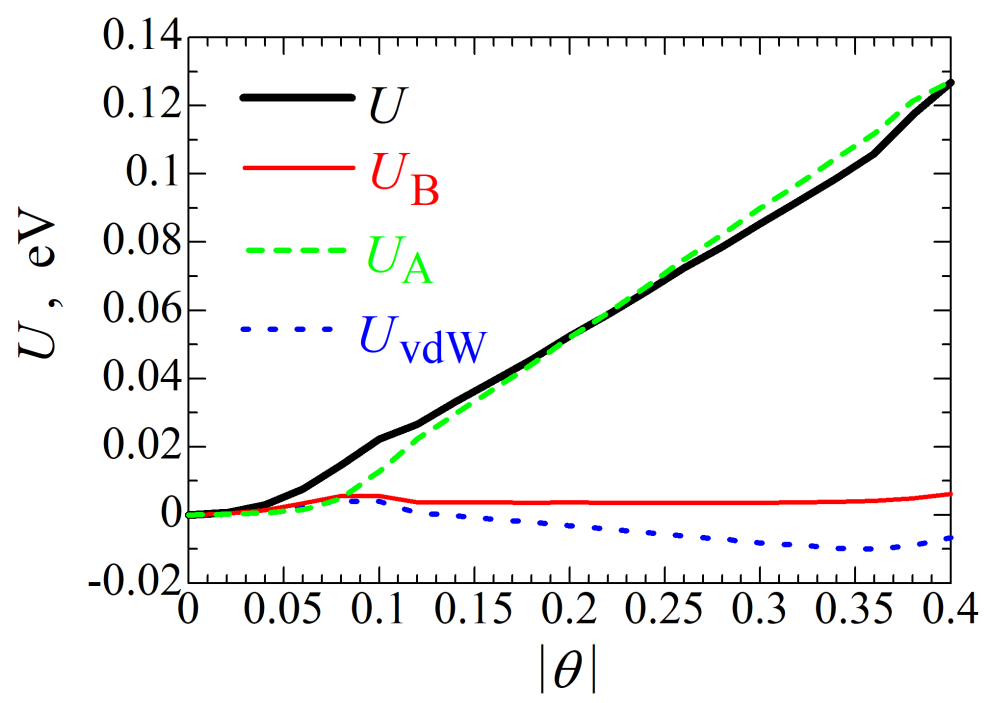

Figure 4. Potential energy of the relaxed CNT bandle and its three components as the functions of volumetric compressive strain. Total energy $U$ is given by the thick black line, the energy of the valence bonds $U_{\mathrm{B}}$ by the thin red line, the energy of valence angles $U_{\mathrm{A}}$ by the green dashed line and the energy of van der Waals interactions $U_{\mathrm{vdW}}$ by the blue dotted line.

It is also instructive to analyze the stress-strain curves which are presented in Figure 5. This curves reflect the two phase transitions in the CNT bundle subject to biaxial compression. The second-order phase transition takes place at $|\theta| \approx 0.07$, when CNTs obtain elliptic form, the translational cell doubles, and the long-range order is still preserved. Stress components do not show discontinuity at this transition point but the slope of the stress-strain curves changes. The first-order phase transition occurs at $|\theta| \approx 0.12$ when sudden drop of the normal stress components is observed due to appearance of the collapsed CNTs. In the regime of compression with increasing fraction of collapsed CNTs normal stress components are almost constant and they start to grow when collapsed CNTs percolate.

We also note that during the whole studied range of compressive strain the equality of normal stress components nearly holds, $\sigma_{x x} \approx \sigma_{y y}$, and shear stress remains nearly zero, $\sigma_{x y} \approx 0$, as it should be for biaxial compression. This means that the considered computational cell size is sufficiently large. 


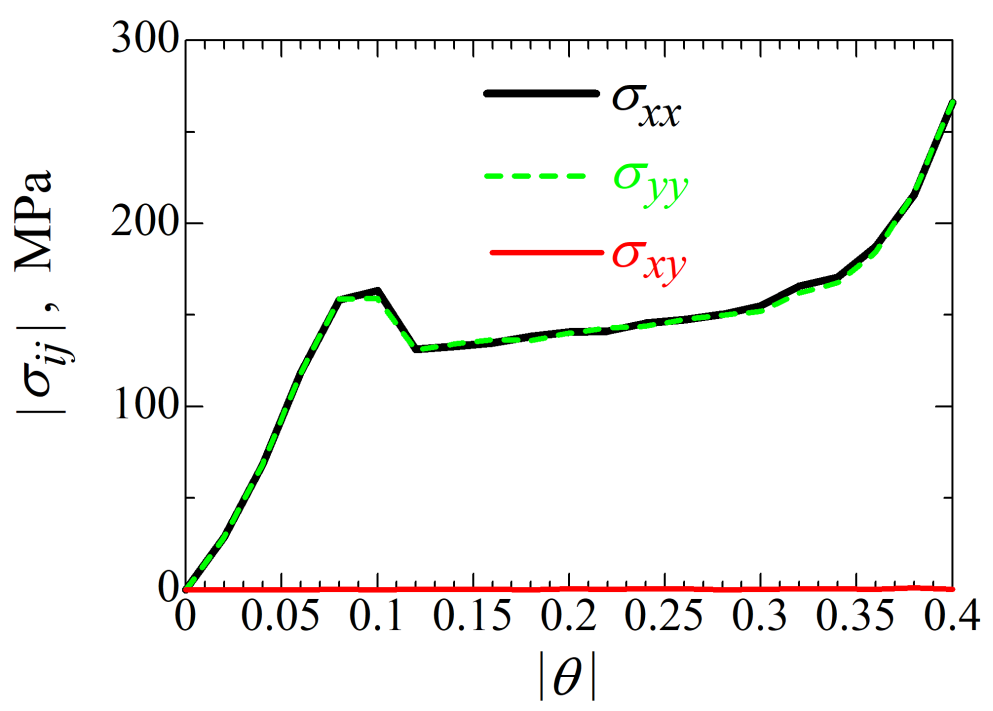

Figure 5. Stress components as the functions of the volumetric compressive strain.

\section{Conclusions}

Relaxational dynamics simulations were performed in the frame of the chain model developed in Refs. $[69,70]$ to analyze the mechanical response of CNT bundle to biaxial compression. It was found that the CNT bundle undergoes two phase transitions. At the value of the compressive volumetric strain of $|\theta| \approx 0.07$ the second-order phase transition was observed. As a result of this transition period doubling took place while crystallinity of the structure was preserved. Cross section of CNTs at the transition point changed from nearly circular (Figure $2 a$ ) to elliptic (Figure $2 b$ ). At $|\theta| \approx 0.12$ the first-order phase transition took place when collapsed CNTs appeared in the system (Figure 2c). Further compression was observed at nearly constant values of normal stress due to the increase in the portion of collapsed CNTs. At $|\theta| \approx 0.4$ all CNTs were found collapsed (Figure $2 \mathrm{~d}$ ).

It was found that the deformation mechanism of CNT bundle was bending of CNT walls with very little tensile deformation of the walls and the main contribution to the potential energy of the system comes from the energy of valence angles, $U_{\mathrm{A}}$, (see Figure 4 ). Van der Waals energy, $U_{\mathrm{vdW}}$, slightly decreased in the regime of growing portion of collapsed CNTs due to formation of new bonds.

The chain model used in the present study assumes that the atomic rows along the armchair direction are rigid. All structures analyzed here correspond to this assumption and, therefore, can be obtained in case of refusal of plane strain conditions. In the case of full atomic modeling CNTs can collapse in another fashion, by initiation of the local collapsed region and its propagation along the tube. If this scenario is energetically favorable, then the first-order phase transition should happen somewhat earlier than in the case of plane strain conditions. Another limitation of the chain model is related to the simulations at finite temperature. Phonon waves propagating along the CNTs are completely suppressed by the plane strain conditions. All these effects should be addressed in frame of a full atomic model. In the present study full atomic simulations were not conducted, but in the previous works with smaller number of degrees of freedom it was shown that in many cases the chain model gives physically meaningful results close to those obtained in full atomic simulations [69-75].

Modification of the chain model to the case of the armchair CNT bundle is straightforward but the model parameters will be somewhat different from that for the zigzag CNTs.

Overall, our results contribute to understanding of the mechanisms of deformation and mechanical response of CNT bundle to lateral compression.

Future research directions include consideration of bundles composed of CNTs of different diameter or multi-walled CNTs. It is possible to modify the chain model used here for modelling other graphene-analogous 2D nanomaterials [76]. Nonlinear dynamics and spatially localized excitations such as discrete breathers and rotobreathers [77] will also be analyzed in CNT bundles. 
Author Contributions: Individual contributions of the authors: conceptualization, S.V.D. and K.Z.; methodology, S.V.D. and K.Z.; software, E.A.K., V.I.D. and D.V.L.; investigation, D.U.A., A.A.K. and E.G.S.; data curation, D.U.A., A.A.K. and E.G.S.; writing-original draft preparation, S.V.D. and K.Z.; visualization, D.U.A. All authors have read and agreed to the published version of the manuscript.

Funding: This research was funded by the Russian Foundation for Basic Research, grant number 18-29-19135.

Acknowledgments: Research of E.G.S. was carried out at Tomsk Polytechnic University within the framework of Tomsk Polytechnic University Competitiveness Enhancement Program grant. E.A.K. acknowledges financial support provided by the Russian Foundation for Basic Research, grant No. 18-29-19135. This work was partly supported by the State Assignment of IMSP RAS No. AAAA-A17-117041310220-8.

Conflicts of Interest: The authors declare no conflict of interest.

\section{References}

1. Pérez, E.M.; Martín, N. Curves ahead: Molecular receptors for fullerenes based on concave-convex complementarity. Chem. Soc. Rev. 2008, 37, 1512-1519. [CrossRef] [PubMed]

2. Lyapin, A.G.; Brazhkin, V.V.; Lyapin, S.G.; Popova, S.V.; Varfolomeeva, T.D.; Voloshin, R.A.; Pronin, A.A.; Sluchanko, N.E.; Gavrilyuk, A.G.; Trojan, I.A. Non-traditional carbon semiconductors prepared from fullerite C60 and carbyne under high pressure. Phys. Status Solidi B 1999, 211, 401-412. [CrossRef]

3. Popov, M.; Koga, Y.; Fujiwara, S.; Mavrin, B.N.; Blank, V.D. Carbon nanocluster-based superhard materials. New Diam. Front. C. Tech. 2002, 12, 229-260.

4. Ferrari, A.C. Raman spectroscopy of graphene and graphite: Disorder, electron-phonon coupling, doping and nonadiabatic effects. Solid State Commun. 2007, 143, 47-57. [CrossRef]

5. Ghosh, S.; Nika, D.L.; Pokatilov, E.P.; Balandin, A.A. Heat conduction in graphene: Experimental study and theoretical interpretation. New J. Phys. 2009, 11, 095012. [CrossRef]

6. Tersoff, J.; Ruoff, R.S. Structural properties of a carbon-nanotube crystal. Phys. Rev. Lett. 1994 73, 676-679. [CrossRef]

7. Thess, A.; Lee, R.; Nikolaev, P.; Dai, H.; Petit, P.; Robert, J.; Xu, C.; Lee, Y.H.; Kim, S.G.; Rinzler, A.G.; et al. Crystalline ropes of metallic carbon nanotubes. Science 1996, 273, 483-487. [CrossRef]

8. Saether, E.; Frankland, S.J.V.; Pipes, R.B. Transverse mechanical properties of single-walled carbon nanotube crystals. Part I: Determination of elastic moduli. Compos. Sci. Technol. 2003, 63, 1543-1550. [CrossRef]

9. Samsonidze, G.G.; Samsonidze, G.G.; Yakobson, B.I. Kinetic theory of symmetry-dependent strength in carbon nanotubes. Phys. Rev. Lett. 2002, 88, 065501. [CrossRef]

10. Shenderova, O.A.; Zhirnov, V.V.; Brenner, D.W. Carbon nanostructures. Crit. Rev. Solid State 2002, 27, $227-356$. [CrossRef]

11. Yu, M.-F. Fundamental mechanical properties of carbon nanotubes: Current understanding and the related experimental studies. J. Eng. Mater. T. ASME 2004, 126, 271-278. [CrossRef]

12. Yu, M.-F.; Lourie, O.; Dyer, M.J.; Moloni, K.; Kelly, T.F.; Ruoff, R.S. Strength and breaking mechanism of multiwalled carbon nanotubes under tensile load. Science 2000, 287, 637-640. [CrossRef] [PubMed]

13. Truong, T.K.; Lee, Y.; Suh, D. Multifunctional characterization of carbon nanotube sheets, yarns, and their composites. Curr. Appl. Phys. 2016, 16, 1250-1258. [CrossRef]

14. Yao, S.; Yuan, J.; Mehedi, H.-A.; Gheeraert, E.; Sylvestre, A. Carbon nanotube forest based electrostatic capacitor with excellent dielectric performances. Carbon 2017, 116, 648-654. [CrossRef]

15. Yao, X.; Hawkins, S.C.; Falzon, B.G. An advanced anti-icing/de-icing system utilizing highly aligned carbon nanotube webs. Carbon 2018, 136, 130-138. [CrossRef]

16. Yao, X.; Falzon, B.G.; Hawkins, S.C.; Tsantzalis, S. Aligned carbon nanotube webs embedded in a composite laminate: A route towards a highly tunable electro-thermal system. Carbon 2018, 129, 486-494. [CrossRef]

17. Rakov, E.G. Materials made of carbon nanotubes. The carbon nanotube forest. Russ. Chem. Rev. 2013, 82, $538-566$. [CrossRef]

18. Chen, H.; Roy, A.; Baek, J.-B.; Zhu, L.; Qu, J.; Dai, L. Controlled growth and modification of vertically-aligned carbon nanotubes for multifunctional applications. Mater. Sci. Eng. R Rep. 2010, 70, 63-91. [CrossRef]

19. Bedewy, M.; Meshot, E.R.; Guo, H.; Verploegen, E.A.; Lu, W.; Hart, A.J. Collective mechanism for the evolution and self-termination of vertically aligned carbon nanotube growth. J. Phys. Chem. C 2009, 113, 20576-20582. [CrossRef]

20. Lan, Y.; Wang, Y.; Ren, Z.F. Physics and applications of aligned carbon nanotubes. Adv. Phys. 2011, 60, 553-678. [CrossRef] 
21. Prudkovskiy, V.S.; Iacovella, F.; Katin, K.P.; Maslov, M.M.; Cherkashin, N. A bottom-up approach for controlled deformation of carbon nanotubes through blistering of supporting substrate surface. Nanotechnology 2018, $29,365304$. [CrossRef] [PubMed]

22. Yu, M.-F.; Files, B.S.; Arepalli, S.; Ruoff, R.S. Tensile loading of ropes of single wall carbon nanotubes and their mechanical properties. Phys. Rev. Lett. 2000, 84, 5552-5555. [CrossRef] [PubMed]

23. Dhanabalan, S.C.; Dhanabalan, B.; Chen, X.; Ponraj, J.S.; Zhang, H. Hybrid carbon nanostructured fibers: Stepping stone for intelligent textile-based electronics. Nanoscale 2019, 11, 3046-3101. [CrossRef]

24. Bai, Y.; Zhang, R.; Ye, X.; Zhu, Z.; Xie, H.; Shen, B.; Cai, D.; Liu, B.; Zhang, C.; Jia, Z.; et al. Carbon nanotube bundles with tensile strength over 80 GPa. Nat. Nanotechnol. 2018, 13, 589-595. [CrossRef] [PubMed]

25. Qiu, L.; Wang, X.; Tang, D.; Zheng, X.; Norris, P.M.; Wen, D.; Zhao, J.; Zhang, X.; Li, Q. Functionalization and densification of inter-bundle interfaces for improvement in electrical and thermal transport of carbon nanotube fibers. Carbon 2016, 105, 248-259. [CrossRef]

26. Cho, H.; Lee, H.; Oh, E.; Lee, S.-H.; Park, J.; Park, H.J.; Yoon, S.-B.; Lee, C.-H.; Kwak, G.-H.; Lee, W.J.; et al. Hierarchical structure of carbon nanotube fibers, and the change of structure during densification by wet stretching. Carbon 2018, 136, 409-416. [CrossRef]

27. Fernández-Toribio, J.C.; Alemán, B.; Ridruejo, Á.; Vilatela, J.J. Tensile properties of carbon nanotube fibres described by the fibrillar crystallite model. Carbon 2018, 133, 44-52. [CrossRef]

28. Dang, Z.-M.; Yuan, J.-K.; Zha, J.-W.; Zhou, T.; Li, S.-T.; Hu, G.-H. Fundamentals, processes and applications of high-permittivity polymer-matrix composites. Prog. Mater. Sci. 2012, 57, 660-723. [CrossRef]

29. Bakshi, S.R.; Lahiri, D.; Agarwal, A. Carbon nanotube reinforced metal matrix composites-A review. Int. Mater. Rev. 2010, 55, 41-64. [CrossRef]

30. Dorri Moghadam, A.; Omrani, E.; Menezes, P.L.; Rohatgi, P.K. Mechanical and tribological properties of self-lubricating metal matrix nanocomposites reinforced by carbon nanotubes (CNTs) and graphene-A review. Compos. Part B: Eng. 2015, 77, 448, 402-420. [CrossRef]

31. Reinert, L.; Lasserre, F.; Gachot, C.; Grützmacher, P.; Maclucas, T.; Souza, N.; Mücklich, F.; Suarez, S. Long-lasting solid lubrication by CNT-coated patterned surfaces. Sci. Rep. 2017, 7, 42873. [CrossRef] [PubMed]

32. Popov, V. Generalized archard law of wear based on Rabinowicz criterion of wear particle formation. Facta Univ. Ser. Mech. Eng. 2019, 17, 39-45. [CrossRef]

33. Wang, B.; Chang, Q.Y.; Gao, K. Synergistic tribological properties of synthetic magnesium silicate hydroxide combined with amphiphilic moleculaes. Facta Univ. Ser. Mech. Eng. 2019, 17, 65-74.

34. Cao, A.Y.; Dickrell, P.L.; Sawyer, W.G.; Ghasemi-Nejhad, M.N.; Ajayan, P.M. Super-compressible foamlike carbon nanotube films. Science 2005, 310, 1307-1310. [CrossRef] [PubMed]

35. Pathak, S.; Kalidindi, S.R. Spherical nanoindentation stress-strain curves. Mater. Sci. Eng. R Rep. 2015, 91, 1-36. [CrossRef]

36. Pathak, S.; Cambaz, Z.G.; Kalidindi, S.R.; Swadener, J.G.; Gogotsi, Y. Viscoelasticity and high buckling stress of dense carbon nanotube brushes. Carbon 2009, 47, 1969-1976. [CrossRef]

37. Maschmann, M.R.; Zhang, Q.; Du, F.; Dai, L.; Baur, J. Length dependent foam-like mechanical response of axially indented vertically oriented carbon nanotube arrays. Carbon 2011, 49, 386-397. [CrossRef]

38. Cao, C.; Reiner, A.; Chung, C.; Chang, S.-H.; Kao, I.; Kukta, R.V.; Korach, C.S. Buckling initiation and displacement dependence in compression of vertically aligned carbon nanotube arrays. Carbon 2011, 49, 3190-3199. [CrossRef]

39. Liang, X.; Shin, J.; Magagnosc, D.; Jiang, Y.; Jin Park, S.; John Hart, A.; Turner, K.; Gianola, D.S.; Purohit, P.K. Compression and recovery of carbon nanotube forests described as a phase transition. Int. J. Solids Struct. 2017, 122-123, 196-209. [CrossRef]

40. Koumoulos, E.P.; Charitidis, C.A. Surface analysis and mechanical behaviour mapping of vertically aligned CNT forest array through nanoindentation. Appl. Surf. Sci. 2017, 396, 681-687. [CrossRef]

41. Pour Shahid Saeed Abadi, P.; Hutchens, S.B.; Greer, J.R.; Cola, B.A.; Graham, S. Buckling-driven delamination of carbon nanotube forests. Appl. Phys. Lett. 2013, 102, 223103. [CrossRef]

42. Silva-Santos, S.D.; Alencar, R.S.; Aguiar, A.L.; Kim, Y.A.; Muramatsu, H.; Endo, M.; Blanchard, N.P.; San-Miguel, A.; Souza Filho, A.G. From high pressure radial collapse to graphene ribbon formation in triple-wall carbon nanotubes. Carbon 2019, 141, 568-579. [CrossRef]

43. Tangney, P.; Capaz, R.B.; Spataru, C.D.; Cohen, M.L.; Louie, S.G. Structural transformations of carbon nanotubes under hydrostatic pressure. Nano Lett. 2005 5, 2268-2273. [CrossRef] 
44. Zhang, S.; Khare, R.; Belytschko, T.; Hsia, K.J.; Mielke, S.L.; Schatz, G.C. Transition states and minimum energy pathways for the collapse of carbon nanotubes. Phys. Rev. B 2006, 73, 075423. [CrossRef]

45. Shima, H.; Sato, M. Multiple radial corrugations in multiwalled carbon nanotubes under pressure. Nanotechnology 2008, 19, 495705. [CrossRef] [PubMed]

46. Zhao, Z.S.; Zhou, X.-F.; Hu, M.; Yu, D.L.; He, J.L.; Wang, H.-T.; Tian, Y.J.; Xu, B. High-pressure behaviors of carbon nanotubes. J. Superhard Mater. 2012, 34, 371-385. [CrossRef]

47. Islam, S.; Saleh, T.; Asyraf, M.R.M.; Mohamed Ali, M.S. An ex-situ method to convert vertically aligned carbon nanotubes array to horizontally aligned carbon nanotubes mat. Mater. Res. Express 2019, 6, 025019. [CrossRef]

48. Zhang, R.; Zhang, Y.; Wei, F. Horizontally aligned carbon nanotube arrays: Growth mechanism, controlled synthesis, characterization, properties and applications. Chem. Soc. Rev. 2017, 46, 3661-3715. [CrossRef] [PubMed]

49. Nam, T.H.; Goto, K.; Yamaguchi, Y.; Premalal, E.V.A.; Shimamura, Y.; Inoue, Y.; Naito, K.; Ogihara, S. Effects of CNT diameter on mechanical properties of aligned CNT sheets and composites. Compos. Part A Appl. Sci. Manuf. 2015, 76, 289-298. [CrossRef]

50. Qiu, L.; Wang, X.; Su, G.; Tang, D.; Zheng, X.; Zhu, J.; Wang, Z.; Norris, P.M.; Bradford, P.D.; Zhu, Y. Remarkably enhanced thermal transport based on a flexible horizontally-aligned carbon nanotube array film. Sci. Rep. 2016, 6, 21014. [CrossRef]

51. Tang, J.; Sasaki, T.; Yudasaka, M.; Matsushita, A.; Iijima, S. Compressibility and polygonization of single-walled carbon nanotubes under hydrostatic pressure. Phys. Rev. Lett. 2000, 85, 1887-1889. [CrossRef] [PubMed]

52. Karmakar, S.; Sharma, S.M.; Teredesai, P.V.; Muthu, D.V.S.; Govindaraj, A.; Sikka, S.K.; Sood, A.K. Structural changes in single-walled carbon nanotubes under non-hydrostatic pressures: X-ray and Raman studies. New J. Phys. 2003, 5, 143.1-143.11. [CrossRef]

53. Qian, D.; Wagner, G.J.; Liu, W.K.; Yu, M.-F.; Ruoff, R.S. Mechanics of carbon nanotubes. Appl. Mech. Rev. 2002, 55, 495-532. [CrossRef]

54. Wittmaack, B.K.; Volkov, A.N.; Zhigilei, L.V. Phase transformation as the mechanism of mechanical deformation of vertically aligned carbon nanotube arrays: Insights from mesoscopic modeling. Carbon 2019, 143, 587-597. [CrossRef]

55. Wittmaack, B.K.; Volkov, A.N.; Zhigilei, L.V. Mesoscopic modeling of the uniaxial compression and recovery of vertically aligned carbon. Compos. Sci. Technol. 2018, 166, 66-85. [CrossRef]

56. Yakobson, B.I.; Brabec, C.J.; Bernholc, J. Nanomechanics of carbon tubes: Instabilities beyond linear response. Phys. Rev. Lett. 1996, 76, 2511-2514. [CrossRef]

57. Rafii-Tabar, H.; Ghavanloo, E.; Fazelzadeh, S.A. Nonlocal continuum-based modeling of mechanical characteristics of nanoscopic structures. Phys. Rep. 2016, 638, 1-97. [CrossRef]

58. Harik, V.M. Ranges of applicability for the continuum beam model in the mechanics of carbon nanotubes and nanorods. Solid State Commun. 2001 120, 331-335. [CrossRef]

59. Ji, J.; Zhao, J.; Guo, W. Novel nonlinear coarse-grained potentials of carbon nanotubes. J. Mech. Phys. Solids 2019, 128, 79-104. [CrossRef]

60. Impellizzeri, A.; Briddon, P.; Ewels, C.P. Stacking- and chirality-dependent collapse of single-walled carbon nanotubes: A large-scale density-functional study. Phys. Rev. B 2019, 100, 115410. [CrossRef]

61. Chopra, N.G.; Benedict, L.X.; Crespi, V.H.; Cohen, M.L.; Louie, S.G.; Zettl, A. Fully collapsed carbon nanotubes. Nature 1995 377, 135-138. [CrossRef]

62. Chang, T. Dominoes in carbon nanotubes. Phys. Rev. Lett. 2008, 101, 175501. [CrossRef] [PubMed]

63. Maslov, M.M.; Grishakov, K.S.; Gimaldinova, M.A.; Katin, K.P. Carbon vs silicon polyprismanes: A comparative study of metallic sp3-hybridized allotropes. Fuller. Nanotub. Car. Nanostructures 2020, 28, 97-103. [CrossRef]

64. Long, R.; Hui, C.-Y. Crack tip fields in soft elastic solids subjected to large quasi-static deformation-A review. Extrem. Mech. Lett. 2015, 4, 131-155. [CrossRef]

65. Chen, C.; Wang, Z.; Suo, Z. Flaw sensitivity of highly stretchable materials. Extreme Mech. Lett. 2017, 10, 50-57. [CrossRef] 
66. Zhang, Y.; Huang, Y.; Zhang, T.; Chang, H.; Xiao, P.; Chen, H.; Huang, Z.; Chen, Y. Broadband and tunable high-performance microwave absorption of an ultralight and highly compressible graphene foam. Adv. Mater. 2015, 27, 2049-2053. [CrossRef]

67. Evazzade, I.; Lobzenko, I.P.; Saadatmand, D.; Korznikova, E.A.; Zhou, K.; Liu, B.; Dmitriev, S.V. Graphene nanoribbon as an elastic damper. Nanotechnology 2018, 29, 215704. [CrossRef]

68. Rysaeva, L.K.; Korznikova, E.A.; Murzaev, R.T.; Abdullina, D.U.; Kudreyko, A.A.; Baimova, J.A.; Lisovenko, D.S.; Dmitriev, S.V. Elastic damper based on carbon nanotube bundle. Facta Univ. Ser. Mech. Eng. 2020, 18, 1-12.

69. Savin, A.V.; Korznikova, E.A.; Dmitriev, S.V. Scroll configurations of carbon nanoribbons. Phys. Rev. B 2015, 92, 035412. [CrossRef]

70. Korznikova, E.A.; Rysaeva, L.K.; Savin, A.V.; Soboleva, E.G.; Ekomasov, E.G.; Ilgamov, M.A.; Dmitriev, S.V. Chain model for carbon nanotube bundle under plane strain conditions. Materials 2019, 12, 3951. [CrossRef]

71. Savin, A.V.; Korznikova, E.A.; Dmitriev, S.V. Simulation of folded and scrolled packings of carbon nanoribbons. Phys. Solid State 2015, 57, 2348-2355. [CrossRef]

72. Savin, A.V.; Korznikova, E.A.; Lobzenko, I.P.; Baimova, Y.A.; Dmitriev, S.V. Symmetric scrolled packings of multilayered carbon nanoribbons. Phys. Solid State 2016, 58, 1278-1284. [CrossRef]

73. Savin, A.V.; Korznikova, E.A.; Dmitriev, S.V.; Soboleva, E.G. Graphene nanoribbon winding around carbon nanotube. Comp. Mater. Sci. 2017, 135, 99-108. [CrossRef]

74. Savin, A.V.; Mazo, M.A. 2D chain models of nanoribbon scrolls. Adv. Struct. Mater. 2019, 94, $241-262$.

75. Savin, A.V.; Korznikova, E.A.; Dmitriev, S.V. Dynamics of surface graphene ripplocations on a flat graphite substrate. Phys. Rev. B 2019, 99, 235411. [CrossRef]

76. Liu, B.; Zhou, K. Recent progress on graphene-analogous 2D nanomaterials: Properties, modeling and applications. Progr. Mater. Sci. 2019, 100, 99-169. [CrossRef]

77. Dmitriev, S.V. Discrete breathers in crystals: Energy localization and transport. J. Micromech. Mol. Phys. 2016, 1, 1630001. [CrossRef]

(C) 2020 by the authors. Licensee MDPI, Basel, Switzerland. This article is an open access article distributed under the terms and conditions of the Creative Commons Attribution (CC BY) license (http:/ / creativecommons.org/licenses/by/4.0/). 